\title{
Contrast of Treatment on Simulated Water by Biological Aerated Filter and Membrane Bio-Reactor
}

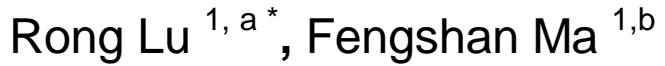 \\ ${ }^{1}$ Key Laboratory Of Institute Shale Gas and Geoengineering, Institute of Geology and Geophysics, \\ Chinese Academy of Sciences,Beijing 100029 \\ alurongwowo@163.com, bfsma@mail.iggcas.ac.cn,
}

\begin{abstract}
Keywords: Biological aerated filter, Membrane bio-reactor, COD removal, TP removal
\end{abstract}
Abstract. Biological aerated filter (BAF) and membrane bio-reactor (MBR) were the common methods at present stage. They were based microbial action to treated raw water. That's common point of two methods. But some difference of treatment effect existed in biological aerated filter (BAF) and membrane bio-reactor (MBR). It's necessary to make a comparison to analysis of difference between two methods. These experiments set some controlled conditions and utilized lab simulated water as experimental raw water. The results of graphs of experiments showed some conclusions: The two methods had very obvious effects to remove chemical oxygen demand (COD). The dissolved oxygen (DO) concentration and chemical oxygen demand (COD) removal had positive correlation. The biological aerated filter (BAF) had better effect than membrane bio-reactor (MBR) to remove total phosphorus (TP). The aim of experiment was analyzed the important indexes treatment and function characteristics then provided some advices to the engineering in the future.

\section{Introduction}

Biological Aerated Filter (BAF), developing on attached growth of biomass on medium, is a wastewater treatment technology emerging in the 1980s and 1990s as an alternative to the traditional wastewater treatment technologies. Conventionally, biological aerated filter (BAF) was submerged media wastewater treatment reactors that combine biological treatment and biomass separation by depth filtration ${ }^{[1]}$. It was easy for biological aerated filter to achieve the high removal rate to organic matters from biodegradable wastewater due to its much higher concentration of active biomass attached to an inert granular media than activated sludge process. Biological aerated filter combined the effects of filtration, bio-oxidation and absorption. That equaled the setting pond, aerated pond and filter basin combined function ${ }^{[2,3,4]}$.

The technology of biological aerated filter belonged to bio-membrane process because in filter microorganism adhered to filter material. This technology gathered several operations of water quality purification. The device of biological aerated filter met the goal of compound and integration design, and achieved the effect of diversification. The indexes of biological aerated filter removed were chemical oxygen demand (COD), suspended solids (SS), total phosphorus (TP), and nitrogen. The advantages of biological aerated filter were higher organic loading, no sludge bulking, more efficient of oxygen transport, better effect of treatment, less area of device occupied and convenient in management ${ }^{[5,6]}$.

Membrane technology was widely used for various treatment and reuse applications. Over the last few years membranes have become recognized as one of the preferred treatment technologies for both municipal and industrial water treatment sectors. Treatment of wastewater using membrane bio-reactor (MBR) process is popular as effluent standard are evolving in stringency and current water conservation measures is giving a strong impetus for water reuse applications . This traditional membrane bio-reactor (MBR) system usually removes organic matter from water but it may fail to achieve the required water quality when exposed to peak and variable organic load as the efficiency of a membrane bio-reactor (MBR) system depends on operating parameters.

Bio-membrane module replaced traditional setting pond. The bio-membrane module could make solid-liquid separation, thus making up weakness that effluent water had unstable quality and 
suspended solids increased. The advantages of membrane bio-reactor (MBR) was that made two operations had effect simultaneously. The two opertings were biodegradation and solid-liquid separation $^{[7,8]}$.

There were some differences between biological aerated filter and membrane bio-reactor in water treatment. The main reason was structural differentiation of devices that leaded to different environment for microbial growth. Especially for total phosphorus (TP) treatment, structural differentiation had obvious influence.

\section{Material and methods}

Experiment and measurement

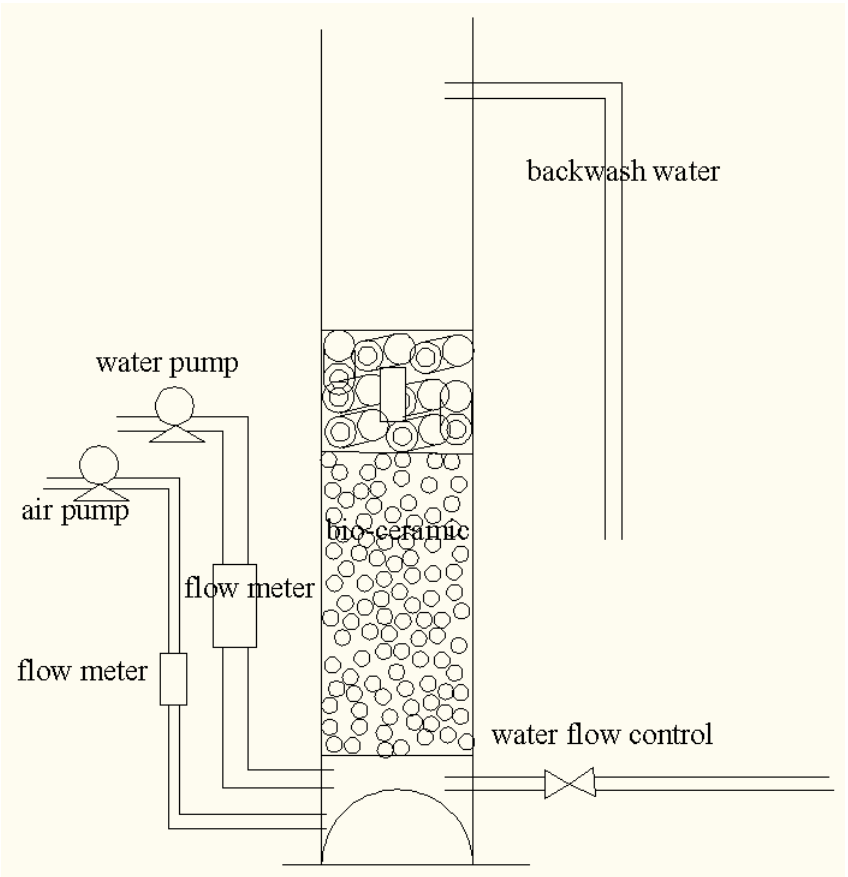

Figure 1. The structural representation of biological aerated filter (BAF)

The schematic diagrams of biological aerated filter (BAF) and membrane bio-reactor (MBR) were presented in figure 1 and figure 2 respectively.

Biological aerated filter provided carrier for microorganism by ceramisite filter material that within the biological aerated filter. The diameter of ceramisite filter material was $3 \sim 5 \mathrm{~mm}$. The The process of biological aerated filter experiment as follows. The experiments took up-water-flow and internal aeration. Biological membrane possessed strong oxidization that could fast depurate water when the raw water through filter. The raw water through filter, filter material guaranteed suspendedmatter removal and biological membrane could not be rushed out. That because filter material had smaller particle size that pressured consolidation by raw water rushed. After a period of time running, the water head loss increased, the biological filter need be back wash to release matter of held back and renew biological membrane.

Membrane component was the most important factor of the membrane bio-reactor that also provided carrier for microorganism. Furthermore, membrane component was barrier film that could obstruct macromolecular contaminants. Settled layer had be accumulated in the membrane component that caused transmembrane pressure increased. But this kind of layer could be cleaned by some physical methods, such as cross flow, aeration. Reactor got less pollution. The aerated conduit of membrane bio-reactor had two functions. The first function that combined oxygen gas with mixed liquor to provided dissolved oxygen gas in the bottom of reactor to rush membrane surface by up-flow gas. This step could maintain the membrane flux. The experiment utilized the flat membrane that possessed some properties, such as, greater stiffness, not easily damaged and anti-pollution ability. To cleaning the 
membrane component, there some difference to biological aerated filter back washing, membrane bio-reactor utilize aeration to ruch to clean the membrane. Several flat sheet membrane module made of hydrophilic modified PVDF were used in this study for membrane bio-reactor (MBR) experiment. The average pore size of the membrane was $0.4 \mu \mathrm{m}$. Air flow was applied to produce shear stress on the membrane surface and to provide oxygen for microorganism for biodegradation of raw water.

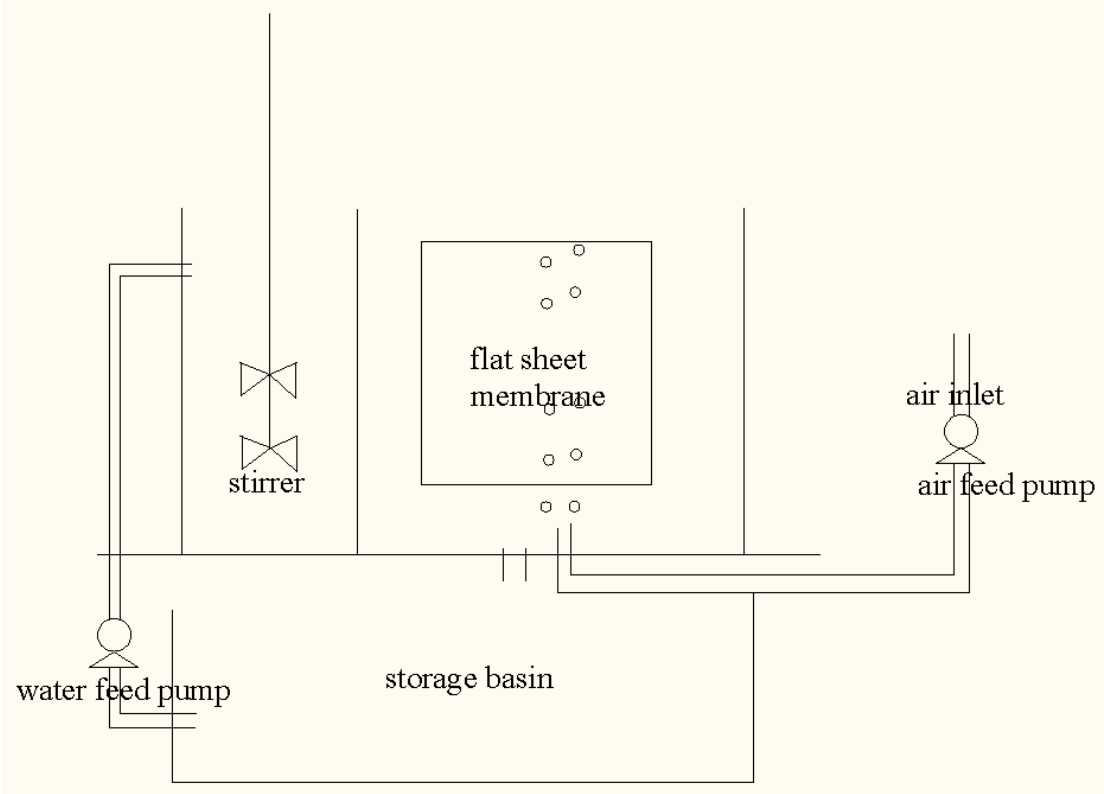

Figure 2. The structural representation of membrane bio-reactor (MBR)

Analytical methods

The main indexes of detection were chemical oxygen demand (COD), dissolved oxygen (DO) and total phosphorus (TP). The analytical methods of these indexes were as follow : The chemical oxygen demand (COD) was tested by the potassium dichromate method. The dissolved oxygen (DO) was tested by the ion-selective electrode method. And the total phosphorus (TP) was tested by ammonium molybdate spectrophotometric method. The analytical instrument was water quality analyzer of $\mathrm{HACH}$ DR3900.

\section{Results and discussion}

The removal of chemical oxygen demand (COD)

Fig3 showed experiment comparison result that different method and different concentration of raw water. The biological aerated filter and membrane bio-reactor used two type of raw water that different concentration respectively. The high concentration of chemical oxygen demand(COD) was $147 \mathrm{mg} / \mathrm{L}$ and the low concentration was $49.5 \mathrm{mg} / \mathrm{L}$. The result showed that: although the raw water concentration was different, the finally effluent water concentration of chemical oxygen demand(COD) all below the $10 \mathrm{mg} / \mathrm{L}$. The mean removal rates were both above $65 \%$ and the highest removal rate was above $90 \%$. This two methods all had obvious effect to chemical oxygen demand(COD) removal. 


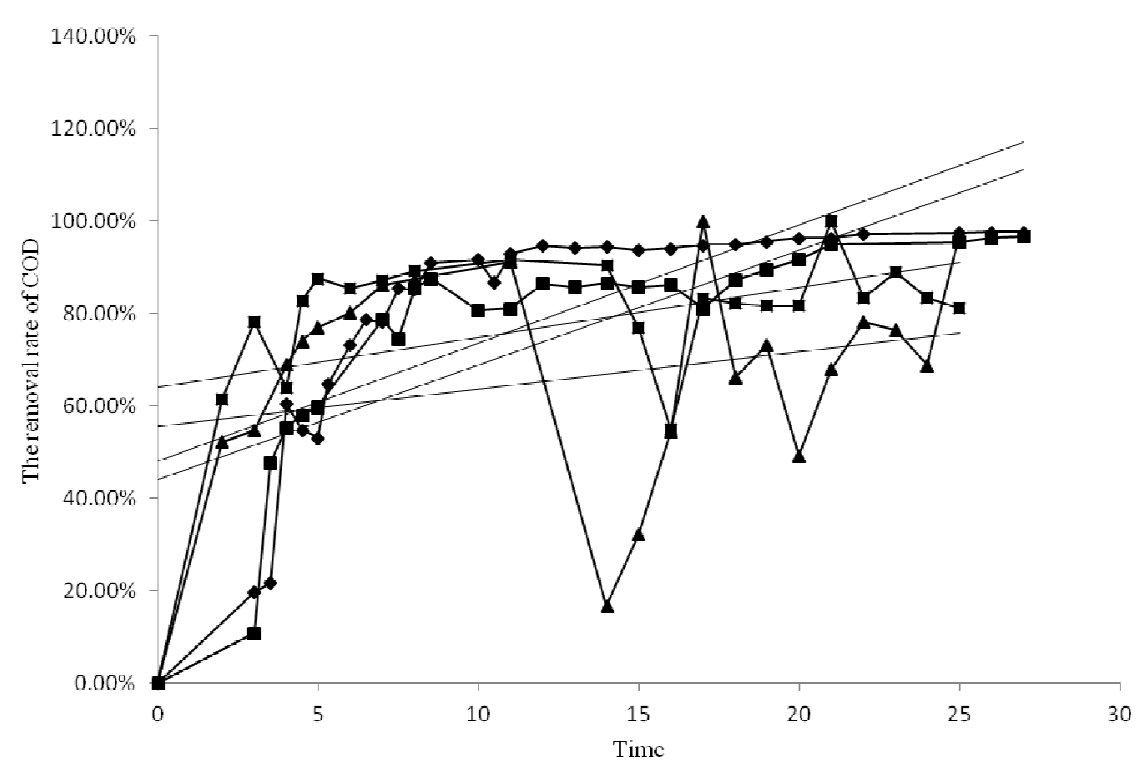

Figure 3. The removal rate of chemical oxygen demand (COD) of biological aerated filter (BAF) and membrane bio-reactor (MBR)

The effluent water results shows process of microorganisms cultured and enriched. chemical oxygen demand(COD) was major index that estimate microorganisms cultured and enriched. Experiment was operated after microbial inoculation. In 5 days, chemical oxygen demand(COD) removal rate increased very fast then the chemical oxygen demand(COD) concentration raised again accompanied removal rate decreased. That showed microorganisms membrane hanging was accomplished.

In the beginning of chemical oxygen demand(COD) removal, the comparison of removal rate showed that as for chemical oxygen demand(COD) removal at this stage, the effect of biological aerated filter was better than membrane bio-reactor, but some days after, the experimental results changed. The analysis of experiment shows that biological aerated filter contained ceramsite that that absorbed chemical oxygen demand(COD) in the beginning of experiment. That's physisorption, not biological function. As microorganisms enriched, the removal effect of two methods almost brought into line.

The relationship of dissolved oxygen (DO) concentration and the removal rate chemical oxygen demand (COD)

By the calculation, when the chemical oxygen demand (COD) concentration of raw water was $147 \mathrm{mg} / \mathrm{L}$, the correlation coefficient for dissolved oxygen (DO) and chemical oxygen demand (COD) of biological aerated filter was 0.7196 , and membrane bio-reactor correlation coefficient for dissolved oxygen (DO) and chemical oxygen demand (COD) was 0.683 . The content of dissolved oxygen (DO) and chemical oxygen demand (COD) removal had better relativity than other water quality indexes. Fig4 was relational graph of dissolved oxygen (DO) and chemical oxygen demand (COD), it was divided four zones according the concentration of dissolved oxygen (DO) and removal of chemical oxygen demand (COD). Along with the time, the increased of removal rate of chemical oxygen demand (COD) accompanied dissolved oxygen (DO) concentration increased. The data points gathered the mean value that was $(1.52125,76.45 \%)$. In experiments, the highest concentration of dissolved oxygen (DO) was $2.05 \mathrm{mg} / \mathrm{L}$, and the highest chemical oxygen demand (COD) removal rate of biological aerated filter (BAF) and membrane bio-reactor (MBR) were $96.71 \%$ and $97.66 \%$ respectively. That's showed in the process of experiment after the data up to the average, the relevance of dissolved oxygen (DO) concentration and chemical oxygen demand (COD) removal rate was decreased. 


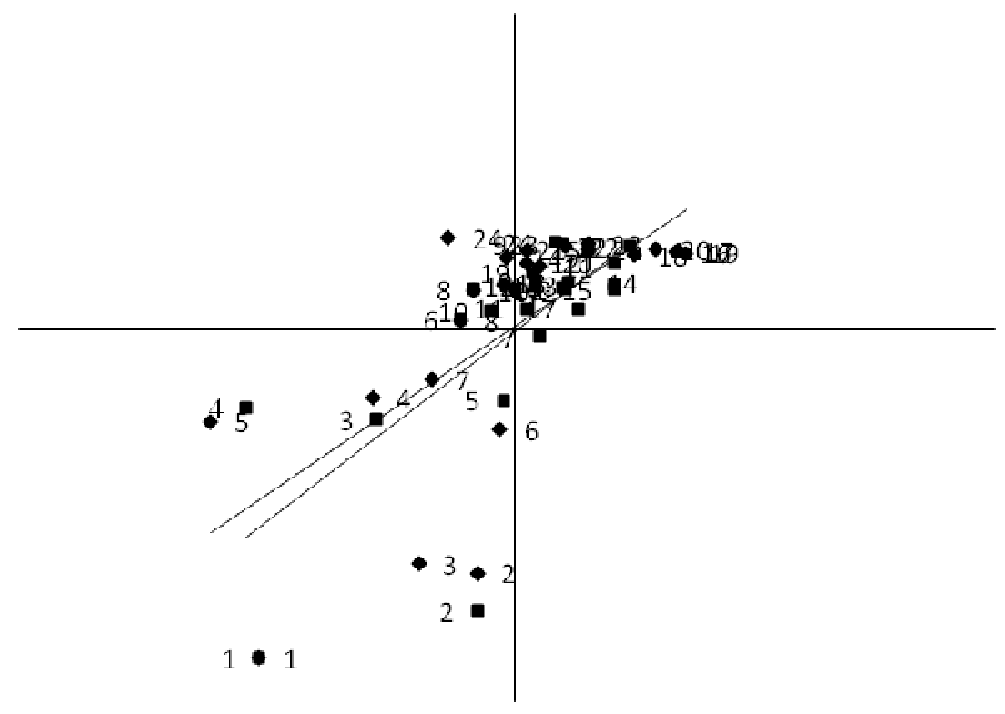

Figure 4. The correlation of dissolved oxygen (DO) concentration and chemical oxygen demand (COD) removal rate.

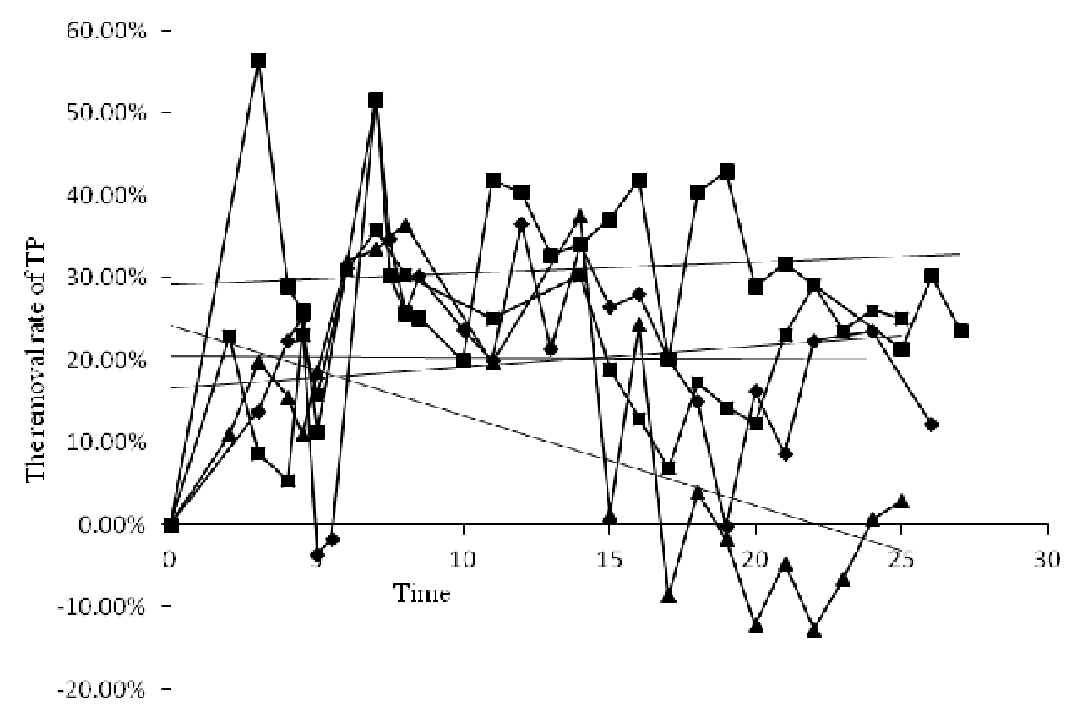

Figure 5. The removal rate of total phosphorus (TP) of biological aerated filter (BAF) and membrane bio-reactor (MBR)

The removal of total phosphorus (TP)

Fig5 showed comparison of effluent flow total phosphorus(TP) concentration. The total phosphorus (TP) concentration were $7.88 \mathrm{mg} / \mathrm{L}$ and $5.6 \mathrm{mg} / \mathrm{L}$ of the raw water. When the raw water total phosphorus (TP) concentration was $7.88 \mathrm{mg} / \mathrm{L}$, biological aerated filter mean removal rate was $32.26 \%$ and the highest removal rate was $56.35 \%$. Membrane bio-reactor mean removal rate was $21.07 \%$ and the highest removal rate was $51.65 \%$. When the raw water total phosphorus (TP) concentration was $5.6 \mathrm{mg} / \mathrm{L}$, biological aerated filter mean removal rate was $20.82 \%$ and the highest removal rate was $35.71 \%$. Membrane bio-reactor mean removal rate was $10.54 \%$ and the highest removal rate was $37.50 \%$. The absorption function of biological membrane and accumulation of phosphorus accumulating bacteria played major part in total phosphorus (TP) removal. The characteristic of phosphorus accumulating bacteria was absorption function only reacted under the aerobic stage. Experimental container developed different microbial growth environment at various stage of the experiment. Within the membrane bio-reactor, the environment easily formed zones depended different oxygen content. Close to the membrane module, environment was aerobic zone and the environment was anoxic zone far from membrane module. Water outlet located in the anoxic zone 
that limited the total phosphorus removal. In general, biological aerated filter had better effect than the membrane bio-reactor in aspect of total phosphorus (TP).

\section{Conclusion}

(1)Biological aerated filter and membrane bio-reactor had obvious effects to remove chemical oxygen demand. The highest removal rates both above $90 \%$.

(2)Dissolved oxygen (DO) concentration and chemical oxygen demand (COD) removal rate had changed during the experiments, but there was positively correlated in general.

(3) The biological aerated filter (BAF) had better effect than membrane bio-reactor (MBR) to remove total phosphorus (TP). Presumptive reason was the difference of device structure that leaded to the different microorganism growth environment.

\section{Acknowledgement}

The research was supported by the Natural Science Foundation of China (Grant No. 41172271). Grateful appreciation is expressed for these supports. The authors would like to thank the institute of hydrogeology and environmental geology, Chinese academy of geological sciences for its financial support.

\section{References}

[1] J. van der Geer, J.A.J. Hanraads, R.A. Lupton, The art of writing a scientific article, J. Sci. Commun. 163 (2000) 51-59.

Reference to a book:

[1] Kok K.N , Xueqing S. A novel application of anaerobic bio- entrapped membrane reactor for the treatment of chemical synthesis-based pharmaceutical wastewater. Separation and Purification Technology 132 (2014)634-643.

[2]Shaoming L , Jincui L. Analysis of up-flow aerated biological activated carbon filter technology in drinking water treatment. Environmental Technology. 34(2013) 2345-2351.

[3]Yaozhong H, Xiaojun W. Application of integrated ozone biological aerated filters and membrane filtration in water reuse of textile effluents. Bioresource Technology. 133(2013) 150-157.

[4]Mohammad A.B , Simin N. Atrazine removal from aqueous solutions using submerged biological aerated filter. Journal of Environmental Health Science and Engineering. 11(2013) 6-15.

[5]Xiaojun W , Jijun H. Combined processes of two-stage Fenton-biological anaerobic filter-biological aerated filter for advanced treatment of landfill leachate. Waste Management. 32(2012) 2401-2405.

[6]Hassimi A.H , Siti R.S.A. Effective microbes for simultaneous bio-oxidation of ammonia and manganese in biological aerated filter system. Bioresource Technology. 124(2012) 355-363.

[7]Pawel K , Jose A.G. Flat sheet or hollow fibre-comparison of full-scale membrane bio-reactor configurations. Desalination and Water Treatment. 42(2012) 100-106.

[8]Santosh R.P , Veeriah J. Performance of reverse osmosis (RO) for water recovery from permeates of membrane bio-reactor (MBR). Desalination and Water Treatment. 52(2014) 600-611. 